\title{
Biochemical recurrence rates are similar for pT2-positive surgical margins and pT3a
}

Katia R. M. Leite, Carolina Hartmann, Sabrina T. Reis, Nayara Viana, Marcos F. Dall'Oglio, Alexandre C. Sant'Anna, Adriano Nesrallah, Luciano Nesrallah, Alberto A. Antunes, Luiz H. Camara-Lopes, Miguel Srougi

Laboratory of Medical Research, Urology - LIM 55, University of Sao Paulo Medical School (KRML, STR, NV, MFD, ACS, AN, AAA, MS) and Genoa Biotechnology (KRML, CH, LN, LHCL), Sao Paulo, Brazil

\section{ABSTRACT}

Objective: Histological details of positive surgical margins in radical prostatectomy specimens have been related to outcome after surgery in rare studies recently published. Our objective is to assess whether the status of surgical margins, the extent and the Gleason score of positive margins, and the extent of the extraprostatic extension are predictive of biochemical recurrence post-radical prostatectomy.

Materials and Methods: Three hundred sixty-five radical prostatectomy specimens were analyzed. The length of the positive surgical margin and extraprostatic extension and the Gleason score of the margin were recorded. Statistical analyses examined the predictive value of these variables for biochemical recurrence.

Results: 236 patients were stage pT2R0, 58 pT2R1, 25 pT3R0 and 46 pT3R1. Biochemical recurrence occurred in 11\%, 31\%, 20\% and 45.7\% of pT2R0, pT2R1, pT3R0 and pT3R1, respectively. The extent of the positive surgical margins and the Gleason score of the positive surgical margins were not associated with biochemical recurrence in univariate analysis in a mean follow up period of 35.9 months. In multivariate analyses, only the status of the surgical margins and the global Gleason score were associated with biochemical recurrence, with a risk of recurrence of 3.1 for positive surgical margins and of 3.8 for a Gleason score $>7$.

Conclusion: Positive surgical margin and the global Gleason score are significant risk factors for biochemical recurrence post-radical prostatectomy, regardless of the extent of the surgical margin, the extent of the extraprostatic extension, or the local Gleason score of the positive surgical margin or extraprostatic tissue. pT2R1 disease behaves as pT3R0 and should be treated similarly.

\section{ARTICLE INFO}

Key words:

Prostatic Neoplasms;

Neoplasm Grading; Prognosis;

Prostatectomy

Int Braz J Urol. 2014; 40: 146-53

Submitted for publication:

April 12, 2013

Accepted after revision:

December 03, 2013

\section{INTRODUCTION}

Between 10 and $40 \%$ of radical prostatectomy specimens will have a positive surgical margin, and margin status has long been predictive of clinical and biochemical recurrence of prostate cancer. However, only $10 \%$ to $40 \%$ of patients with positive surgical margins experience a recurrence $(1,2)$. These numbers indicate that up to $90 \%$ of men who receive adjuvant treatment are overtreated. Some histological markers within the surgical margins and extraprostatic extension have been considered predictors of tumor behavior. Additionally, the International Society of Urological Pathology has recently recommended reporting the length of positive surgical margins in millimeters since there are evidences that it could be important in defining tumor behavior after surgery 
(3). However, few studies have addressed its ability to provide additional prognostic information. The use of the positive surgical margins Gleason score was also recently proposed to improve the accuracy of predictions of radical prostatectomy (4).

Extraprostatic extension has been considered an important prognostic factor related to biochemical recurrence and studies demonstrate that adjuvant radiotherapy could improve the outcome of patients after surgery (5-7). There are very few studies evaluating the predictive power of the extraprostatic extension length or Gleason score as a tool for risk stratification and or as an accurate indicator for adjuvant therapy in this group of patients.

Our objective was to explore the importance of histological details as predictors of biochemical recurrence in men treated for prostate cancer by open radical prostatectomy. Factors considered included the length and Gleason score of positive surgical margins and the length in millimeters and the Gleason score of extraprostatic extension.

\section{MATERIALS AND METHODS}

This is a retrospective study that reviewed the histology slides of surgical specimens from 365 men who consecutively underwent open radical prostatectomy by the same surgeon (MS) between January 2004 and December 2006. The demographic, laboratory and histological data are represented in Table-1. The surgical specimens were fixed in 10\% buffered formalin, and the entire surgical margin was stained with India ink. The bladder neck margin was collected as a thinly shaved section. The most distal portion (5-6mm) of the prostate's apex was amputated and then sectioned parallel to the urethra at $2-3 \mathrm{~mm}$ intervals. The prostate's left and right lobes were separated, $3 \mathrm{~mm}$ transverse serial sections were taken from each lobe, and the entire gland was submitted for histological examination. The Gleason score was used for histological grading. The tumor's volume was measured as previously described (8). Briefly, a grid was placed beneath slides in which the area comprising the tumor had been previously outlined. The percentage of the tumor on a slide was determined by dividing the number of grid squares overlapping the tumor by the number of squares overlapping the entire tissue section. Tumor volume was defined as the mean percentage of tumor in the prostate gland. Extraprostatic involvement was defined as tumor infiltration into the adipose tissue, the neurovascular plexus, or the parenchyma of the seminal vesicles. The TNM 2010 system was used for tumor staging. Patients were classified as pT2 when the tumor was confined to the prostate and pT3 when an extraprostatic extension was apparent or if the seminal vesicles were infiltrated by tumor. Positive surgical margins were considered when tumor glands were inked with India ink (Figure-1A). The length of the positive surgical margins and the extraprostatic extension of each subject was measured using a micrometer ruler (Figure-1B), and the higher radial

Table 1 - Demographic laboratory and histological characteristics of 365 patients submitted to radical prostatectomy to treat prostate cancer.

\begin{tabular}{|c|c|c|c|c|c|c|c|}
\hline & $\begin{array}{c}\text { Age } \\
\text { (Years) }\end{array}$ & $\begin{array}{l}\text { Gleason } \\
\text { Score }\end{array}$ & $\begin{array}{c}\% \text { Gleason } 4 \\
\text { or } 5\end{array}$ & Tumor Volume (\%) & $\begin{array}{l}\text { PO PSA } \\
\text { (ng/mL) }\end{array}$ & $\begin{array}{l}\text { Follow-up } \\
\text { (months) }\end{array}$ & $\begin{array}{c}\text { PSA in BR } \\
(\mathrm{ng} / \mathrm{mL})\end{array}$ \\
\hline Mean & 60.7 & 7 & 47.3 & 14.1 & 6.6 & 35.9 & 1.7 \\
\hline SD & 7.9 & 0.9 & 36.7 & 11.4 & 4.2 & 23.1 & 5.2 \\
\hline Median & 61 & 7 & 46 & 12 & 5.4 & 36.1 & 0.6 \\
\hline Minimum & 42 & 4 & 0 & 0.1 & 0.5 & 1.2 & 0.2 \\
\hline Maximum & 82 & 10 & 100 & 80 & 29 & 78.7 & 42 \\
\hline
\end{tabular}

$\mathbf{P O}=$ pre-operative $\mathbf{B R}=$ Biochemical recurrence 


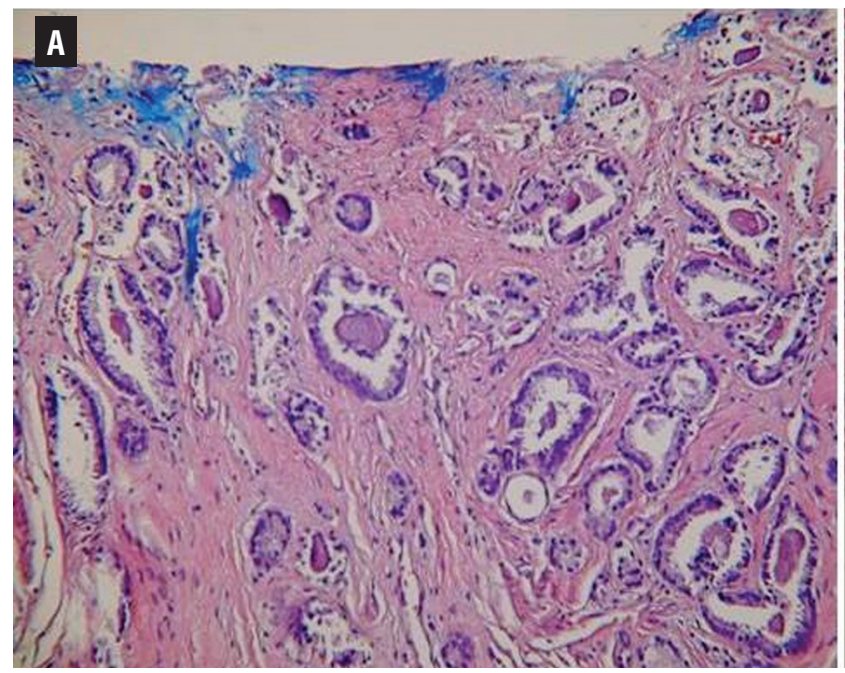

extent was considered when an extraprostatic extension was present. Taking the end of fibromuscular tissue of the prostate at the initial point the tumor was present at the adipose extraprostatic tissue was measured. When multifocal, the sum of all numbers was considered for statistical analysis. For evaluation of the Gleason score in subjects with both a positive surgical margin and an extraprostatic extension, the higher Gleason score was recorded. Unilateral or bilateral involvement of surgical margins and extraprostatic extension were also recorded for evaluation. The goal was to define which variables were predictive of biochemical recurrence. There was no adjuvant treatment before biochemical recurrence. Statistical analysis was performed with SPSS 19.0 software, using $\mathrm{T}$ test tests for normally distributed data and the Mann-Whitney U test for data that were not normally distributed. Kaplan-Meier curves were used to analyze biochemical recurrence risk. The logistic regression was used for multivariate analyses.

\section{RESULTS}

Two-hundred-and-ninety-four (80.5\%) patients were staged pT2. Fifty eight (19.7\%) had a positive surgical margin, with bilateral involvement in 8 (13.8\%). The mean length of the positive

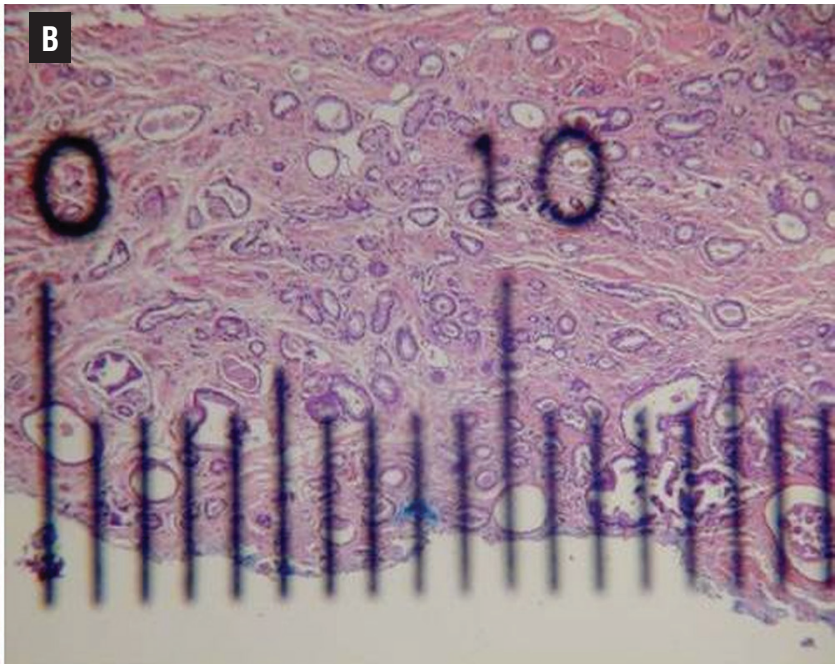

surgical margins was $4.0 \mathrm{~mm}( \pm 3.9 \mathrm{~mm})$. The median length was $3.0 \mathrm{~mm}$ (0.1 to $15.0 \mathrm{~mm})$. The mean Gleason score of the positive surgical margins was 7.1 ( \pm 0.9 ), and the median was 7(6 to 9).

Seventy-one (19.5\%) patients were staged pT3, and $46(64.8 \%)$ had a positive surgical margin. In 25 (35.2\%) patients, there was involvement of the seminal vesicles and were staged pT3b, and one $(1.4 \%)$ patient presented with lymph node metastasis and weas staged pT3bN1. The extraprostatic extension was bilateral in $13(18.3 \%)$ patients. The mean extraprostatic extension length was $19.5 \mathrm{~mm}( \pm 18.5 \mathrm{~mm})$, and the median was $13.8 \mathrm{~mm}$ (2.4 to $78 \mathrm{~mm}$ ). The mean Gleason score of the extraprostatic extension was $8.2( \pm 0.7)$, and the median was 8 (6 to 10$)$. In 13 (18.3\%) patients, the positive surgical margin was bilateral. The mean length of the positive surgical margin was $5 \mathrm{~mm}( \pm 6.8 \mathrm{~mm})$, and the median was $3 \mathrm{~mm}$, ranging from 0.2 to $32 \mathrm{~mm}$. The mean Gleason score of the positive surgical margin was $8( \pm 1.1)$, with a median of 8 (6 to 10).

During a mean follow-up of 35.9 months $( \pm 23.1 \mathrm{~m}), 68(18.6 \%)$ patients experienced recurrence, and their mean PSA levels were $1.7 \mathrm{ng} / \mathrm{mL}$ $( \pm 5.2 \mathrm{ng} / \mathrm{mL})$ (Table-2). There was clinical recurrence in $8(11.7 \%)$ patients, with five local recurrence and two lung and one bone metastases. The 
Table 2 - Univariate analysis relating biochemical recurrence with clinical and pathologic characteristics.

\begin{tabular}{|c|c|c|c|}
\hline & $\begin{array}{c}\text { Yes } \\
(68-18.6 \%)\end{array}$ & $\begin{array}{c}\text { No } \\
(297-81.4 \%)\end{array}$ & $p$ value \\
\hline \multicolumn{4}{|l|}{$\mathrm{pT}$ and margin status } \\
\hline pT2-R0 (236) & $10.6 \%$ & $89.4 \%$ & $<0.001$ \\
\hline pT2-R1 (58) & $31.0 \%$ & $69.0 \%$ & \\
\hline pT3-R0 (25) & $20.0 \%$ & $80.0 \%$ & \\
\hline pT3-R1 (46) & $43.5 \%$ & $56.5 \%$ & \\
\hline Age (years old) & & & 0.539 \\
\hline Mean (SD) & $61.3(7.7)$ & $61.0(8.0)$ & \\
\hline Median (range) & $63(45-77)$ & $60(42-82)$ & \\
\hline Pre operatory PSA (ng/mL) & & & $<0.001$ \\
\hline Mean (SD) & $8.5(5.6)$ & $6.0(3.7)$ & \\
\hline Median (range) & $6(3-29)$ & $5(1-27)$ & \\
\hline Tumor volume (\%) & & & $<0.001$ \\
\hline Mean (SD) & $18.8(12.6)$ & $13.0(10.8)$ & \\
\hline Median (range) & $15(1-55)$ & $11(0.1-80)$ & \\
\hline Gleason score & & & $<0.001$ \\
\hline Mean (SD) & $7.6(0.9)$ & $7.0(0.8)$ & \\
\hline Median (range) & $8(6-10)$ & $7(4-10)$ & \\
\hline \%Gleason 4 or 5 & & & $<0.001$ \\
\hline Mean (SD) & $73.7(29.2)$ & $41.0(35.4)$ & \\
\hline Median (range) & $80(0-100)$ & $38(0-100)$ & \\
\hline Gleason at PSM mean & & & 0.296 \\
\hline Mean (SD) & $8.0(1.0)$ & $8.0(1.0)$ & \\
\hline Median (range) & $8(6-10)$ & $8(6-10)$ & \\
\hline Length of PSM (mm) & & & 0.713 \\
\hline Mean (SD) & $5.0(5.4)$ & $6.0(7.6)$ & \\
\hline Median (range) & $3(0.2-19)$ & $5(1-32)$ & \\
\hline PSM bilateral & & & 0.208 \\
\hline Yes (\%) & 23.8 & 38.7 & \\
\hline Length of EPE (mm) & & & 0.008 \\
\hline Mean (SD) & $14.3(19.2)$ & $7.0(10.9)$ & \\
\hline Median (range) & $6(0.1-78)$ & $4(0.1-78)$ & \\
\hline \multicolumn{4}{|l|}{ EPE bilateral } \\
\hline Yes (\%) & 26.1 & 28.6 & 0.819 \\
\hline
\end{tabular}


multivariated analysis demonstrated that only the status of the margin $(p<0.001)$ and the global Gleason score $(p=0.008)$ were independently related to the biochemical recurrence. The Cox risk of biochemical recurrence was 3.1 for positive surgical margins and 3.8 for a Gleason score $>7$. The Kaplan Meier curves (Figure-2) demonstrate higher survival rates in patients with negative surgical margins, regardless of tumor stage. The estimated recurrence-free survival time for pT2M(-) and $\mathrm{M}(+)$ patients was 70.4 and 59.4 months, respectively. For pT3M(-) and pT3M(+) patients, the recurrence-free survival time was 58.6 and 48.1 months, respectively.

\section{DISCUSSION}

Although 60 to $70 \%$ of prostate tumor patients will be cured with radical prostatectomy alone, adjuvant radiotherapy before biochemical recurrence has been recommended based on three randomized trials conducted by the Southwest Oncology Group, the European Organization for Research and Treatment of Cancer and the German Cancer Society (5-7). The pre-operative PSA levels, tumor stage, Gleason score, and positive surgical margins are all important predictors of tumor recurrence. However, histological details, such as the length of the positive surgical margins or extraprostatic extension and the Gleason score of these areas, have rarely been examined as potential predictors to identify patients more susceptible to recurrence. Following detailed evaluations of 365 surgical specimens, we showed that margin status, independent of extension in millimeters and the Gleason score were independently related to tumor recurrence after radical prostatectomy. Risk of recurrence was 3.1 and 3.8 for positive surgical margins and for Gleason score higher than 7, respectively. Interestingly, we found that even in organconfined tumors, when the margin was positive, the rate of biochemical recurrence was the same as in pT3 negative margin tumors. This finding illustrates the importance of a positive margin in prostate cancer outcomes. Similarly, Grossfeld et al. showed a risk of tumor recurrence of 2.6 for positive surgical margins independently of all
Figure 2 - A) Kaplan Meier curve showing biochemical recurrence for tumors 1. pT2R0; 2. pT2R1; 3. pT3RO and 4. pT3R1. B) Kaplan Meier curve showing biochemical recurrence for tumors $\mathbf{0}$. Negative margin 1 . Positive margin.
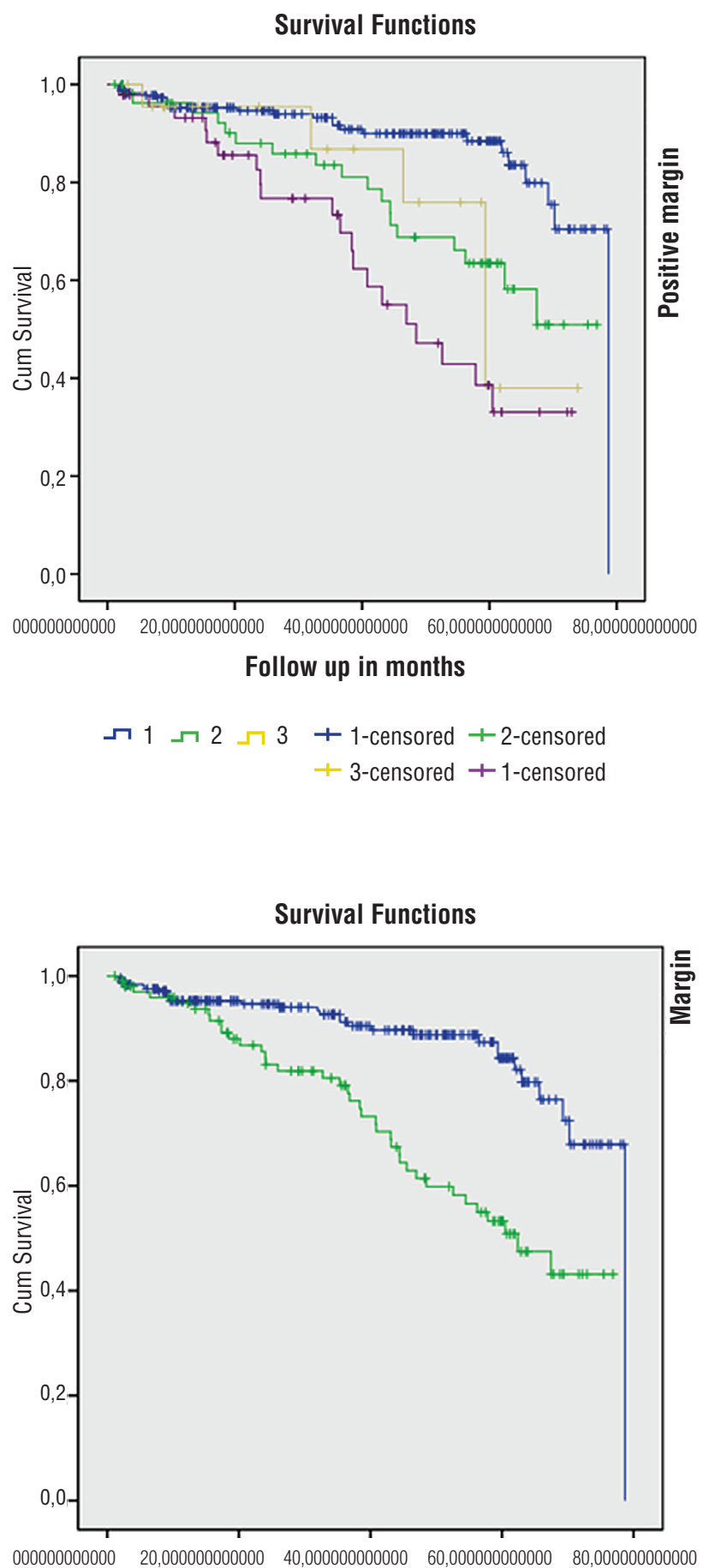

Follow up in months

$\neg$ ת 1 + 0-censored + 1-censored 
other prognostic factors (1). Adjuvant radiotherapy reduces metastasis and improves survival at 10 years, with no impact on quality of life (9). However, accurate selection of men who will benefit from a second treatment is crucial, and this problem has not yet been solved.

Randomized trials often use non-standardized methods to examine surgical specimens, so the true status of surgical margins is not always completely accurate. There are different methods of examination that have not been fully explored in the previous reports. Furthermore, inclusion of the whole gland in the analysis, which would guarantee adequate evaluation of the specimens, is never mentioned in the literature. This lack of information regarding the real tumor status makes the evaluation of results of adjuvant treatment difficult to judge. As a result, patients may be over treated.

Recently, the International Society of Urological Pathology has recommended reporting the length of positive surgical margins as a quantitative measure of the extent of a positive surgical margin (3). However, few studies have demonstrated the real power of these details to predict biochemical recurrence in prostate cancer. In our study, we have shown that some histological details, such as the extent of the positive surgical margin, are not accurate predictors of tumor outcomes. We have also shown that the simple identification of the tumor by India ink staining would be enough to determine whether a patient will benefit from adjuvant radiotherapy. Conversely, Cao et al. examined 294 similar specimens and reported that the length of positive surgical margins was independently related to biochemical recurrence, most importantly in organ-confined tumors (10). Because the study of Cao et al. only included patients with a positive surgical margin, other important determinants of tumor behavior were excluded, thus weakening the statistical evaluation of all other important clinical and pathological details. Shikavov et al. also described that length of positive surgical margin was important to predict biochemical recurrence (11). Ochiai et al. showed that a positive surgical margin length of $3.0 \mathrm{~mm}$ would better distinguish the risk groups
(12). On the other hand, Marks et al. reported that the length of positive surgical margin was not an independent predictive factor of biochemical recurrence, in accordance with our results (13).

We did not find that bilateral involvement of surgical margins had any importance in determining biochemical recurrence. Similar to previous reports, we did not observe a higher risk for disease recurrence if multiple positive margins were present $(1,14)$. In contrast, Lowe and Lieberman reported that the number of positive margins had an important impact on disease recurrence (15).

The Gleason score of the surgical margin has recently been reported as important in predicting biochemical recurrence $(4,16)$. Conversely, we found no relationship between the Gleason score of positive surgical margins and biochemical recurrence. This is the third study evaluating the potential importance of the Gleason score of surgical margins, and future larger studies should be conducted to further examine the importance of this relationship in the prediction of prostate cancer outcomes.

Our results suggest that the length, the bilateral involvement, and the Gleason score of positive surgical margins have no significant impact on biochemical recurrence. Therefore, these values should not be used to indicate adjuvant treatment after radical prostatectomy. The same result was recently published by Udo et al. (17). We found that the status of surgical margins and the Gleason score were the main risk factors for biochemical recurrence, representing a risk of 3.1. This assessment agrees with the risk previously reported in the literature (2). Large patient cohort studies confirm that positive surgical margins are an independent predictor of cancer recurrence, regardless of other factors. Blute et al. examined more than 2,500 patients with a positive margin rate of $39 \%$. The 5-year, disease-free survival rate was $67 \%$ vs. $84 \%$ for positive surgical margins, with a hazards ratio of 1.72 for biochemical recurrence (14). Positive surgical margins were recently included in a 10-year postoperative nomogram as independent predictors of biochemical recurrence (18). 
We have shown that biochemical recurrence rates were not significantly different between patients with pT2 positive margins and pT3 negative surgical margins. It is important to note that positive surgical margins in lateral areas of the prostate gland were staged as pT2 and not pT3 because it is not possible to show tumor extension into extraprostatic tissue. It is recommended that this status be named $\mathrm{pT} 2+$ or pT2R1 meaning residual microscopic disease. Our data show that prostate cancer staged pT2 with a positive surgical margin had similar outcomes as pT3 margin-negative cancers, and thus should be managed as a pT3 disease.

We have shown that the status of the surgical margin is important, even in tumors not confined to the prostate. This finding is similar to other studies that also reported that margin status is important regardless of the tumor stage $(19,20)$.

In conclusion, the status of surgical margins and the Gleason score are independently related to biochemical recurrence in prostate cancer, regardless of other details, such as the extension of positive surgical margins, the length of extraprostatic extension, or the Gleason score present in specific areas. Moreover, adenocarcinoma staged pT2R 1 behaves as pT3R0 and should be treated similarly.

\section{CONFLICT OF INTEREST}

None declared.

\section{REFERENCES}

1. Grossfeld GD, Chang JJ, Broering JM, Miller DP, Yu J, Flanders SC, et al.: Impact of positive surgical margins on prostate cancer recurrence and the use of secondary cancer treatment: data from the CaPSURE database. J Urol. 2000; 163: 1171-7.

2. Chang SS, Cookson MS: Impact of positive surgical margins after radical prostatectomy. Urology. 2006; 68: 249-52.

3. Tan PH, Cheng L, Srigley JR, Griffiths D, Humphrey PA, van der Kwast TH, et al.: International Society of Urological Pathology (ISUP) Consensus Conference on Handling and Staging of Radical Prostatectomy Specimens. Working group 5: surgical margins. Mod Pathol. 2011; 24: 48-57.
4. Savdie R, Horvath LG, Benito RP, Rasiah KK, Haynes AM Chatfield $\mathrm{M}$, et al.: High Gleason grade carcinoma at a positive surgical margin predicts biochemical failure after radical prostatectomy and may guide adjuvant radiotherapy. BJU Int. 2012; 109: 1794-800.

5. Thompson IM, Tangen CM, Paradelo J, Lucia MS, Miller G, Troyer D, et al.: Adjuvant radiotherapy for pathological T3NOMO prostate cancer significantly reduces risk of metastases and improves survival: long-term followup of a randomized clinical trial. J Urol. 2009; 181: 956-62.

6. Bolla M, van Poppel H, Collette L, van Cangh P, Vekemans K, Da Pozzo L, et al.: Postoperative radiotherapy after radical prostatectomy: a randomised controlled trial (EORTC trial 22911). Lancet. 2005 13-19; 366: 572-8.

7. Wiegel T, Bottke D, Steiner U, Siegmann A, Golz R, Störkel $S$, et al.: Phase III postoperative adjuvant radiotherapy after radical prostatectomy compared with radical prostatectomy alone in pT3 prostate cancer with postoperative undetectable prostate-specific antigen: ARO 96-02/AUO AP 09/95. J Clin Oncol. 2009; 27: 2924-30.

8. Humphrey PA, Vollmer RT: Intraglandular tumor extent and prognosis in prostatic carcinoma: application of a grid method to prostatectomy specimens. Hum Pathol. 1990; 21: 799-804.

9. Daly T, Hickey BE, Lehman M, Francis DP, See AM: Adjuvant radiotherapy following radical prostatectomy for prostate cancer. Cochrane Database Syst Rev. 2011; 12: CD00723.

10. Cao D, Humphrey PA, Gao F, Tao Y, Kibel AS: Ability of linear length of positive margin in radical prostatectomy specimens to predict biochemical recurrence. Urology. 2011; 77: 1409-14.

11. Shikanov S, Song J, Royce C, Al-Ahmadie H, Zorn K, Steinberg $G$, et al.: Length of positive surgical margin after radical prostatectomy as a predictor of biochemical recurrence. J Urol. 2009; 182: 139-44.

12. Ochiai A, Sotelo T, Troncoso P, Bhadkamkar V, Babaian RJ: Natural history of biochemical progression after radical prostatectomy based on length of a positive margin. Urology. 2008; 71: 308-12.

13. Marks RA, Koch MO, Lopez-Beltran A, Montironi R, Juliar BE, Cheng $L$ : The relationship between the extent of surgical margin positivity and prostate specific antigen recurrence in radical prostatectomy specimens. Hum Pathol. 2007; 38: 1207-11.

14. Blute ML, Bostwick DG, Bergstralh EJ, Slezak JM, Martin SK, Amling $\mathrm{CL}$, et al.: Anatomic site-specific positive margins in organ-confined prostate cancer and its impact on outcome after radical prostatectomy. Urology. 1997; 50: 733-9.

15. Lowe BA, Lieberman SF: Disease recurrence and progression in untreated pathologic stage T3 prostate cancer: selecting the patient for adjuvant therapy. J Urol. 1997; 158: 1452-6.

16. Cao D, Kibel AS, Gao F, Tao Y, Humphrey PA: The Gleason score of tumor at the margin in radical prostatectomy is predictive of biochemical recurrence. Am J Surg Pathol. 2010; 34: 994-1001. 
17. Udo K, Cronin AM, Carlino LJ, Savage CJ, Maschino AC, AlAhmadie HA, et al.: Prognostic impact of subclassification of radical prostatectomy positive margins by linear extent and Gleason grade. J Urol. 2013; 189: 1302-7.

18. Stephenson AJ, Scardino PT, Eastham JA, Bianco FJ Jr, Dotan ZA, DiBlasio CJ, et al.: Postoperative nomogram predicting the 10-year probability of prostate cancer recurrence after radical prostatectomy. J Clin Oncol. 2005; 23: 7005-12.

19. D'Amico AV, Whittington $R$, Malkowicz SB, Fondurulia $\mathrm{J}$, Chen MH, Tomaszewski JE, et al.: The combination of preoperative prostate specific antigen and postoperative pathological findings to predict prostate specific antigen outcome in clinically localized prostate cancer. J Urol. 1998; 160: 2096-101.
20. Swindle P, Eastham JA, Ohori M, Kattan MW, Wheeler T, Maru $\mathrm{N}$, et al.: Do margins matter? The prognostic significance of positive surgical margins in radical prostatectomy specimens. J Urol. 2008; 179: S47-51.
Correspondence address:

Katia Ramos Moreira Leite, MD Av. Dr. Arnaldo 455 / 2145

São Paulo, SP, 01246-903, Brazil

Telephone: +55 11 3061-7183

E-mail: katiaramos@uol.com.br 